\title{
Preliminary Study on Wound Healing Activity of Propolis in Albino Rats
}

\author{
A.Timucin ATAYOGLU ${ }^{* 1}$, Sibel SILICI ${ }^{2}$ \\ ${ }^{1}$ Asst. Professor in the Department of Family Medicine, Medical Faculty, Medipol University, Istanbul, Turkey \\ ${ }^{2}$ Full Professor in the Department of Agricultural Biotechnology, Faculty of Agriculture, Erciyes University, Kayseri, Turkey
}

\section{Corresponding Author:}

Dr A.Timucin Atayoglu is the Asst. Professor in the Department of Family Medicine, Medical Faculty, Medipol University, Istanbul, Turkey. He is currently the president of the Turkish Apitherapy Association and the director of the Turkish Holistic and Integrative Medicine Association.

\begin{abstract}
:-
Background: Infection can lead to delayed wound healing. Recently it has been shown that propolis which is used in complementary medicine has an antibacterial and anti-inflammatory effect. The aim of this study is to determine whether propolis may contribute to wound healing.

Material and Methods: Twenty-one male Wistar albino rats were randomly divided into three groups. Groupl and Group 2 were topically treated with propolis ointment and Thiocillin ${ }^{\circledR}$ oinment, respectively while Group 3 was the control group. On incision wound model, Thiocillin ${ }^{\circledR}$ and propolis ointments were applied on wound sites once daily for 30 days and the mean epidermal thickness (MET) at the 30th day was compared while antimicrobial activity of propolis was studied against different pathogens as well.
\end{abstract}

Results: Propolis exhibited in vitro antibacterial activity against Staphylococcus aureus, Escherichia coli, Streptococcus sp. and Pseudomonas sp. It is observed that the MET in the groups of Propolis ointment and Thiocillin ${ }^{\circledR}$ ointment were significantly greater than that of the control group, while the MET in the group of propolis ointment was significantly greater than that of Thiocillin ${ }^{\circledR}$ ointment treated group. Conclusion: Propolis is effective in wound healing. Further study in-depth is necessary to probe into clinical correlation.

Keywords: propolis, integrative, complementary medicine, wound healing, antibacterial activity.

\section{Introduction}

Wound healing is a process which consists of an orderly progression of events that re-establish the integrity of the damaged tissue. Normally that process can be broadly categorized into three stages which contain highly integrated and overlapping phases of cellular and biochemical activities including; inflammatory stage (consisting the establishment of homeostasis and inflammation); proliferate stage (consisting of granulation, contraction and epithelisation) and finally the maturation or remodeling stage which ultimately determines the strength and appearance of the healed tissue [1]. Wound healing is a complex series of reactions and interactions among cells and mediators: inflammatory mediators (cytokines, growth factors, proteases, eicosanoids, kinins, and more), nitric oxide, and the cellular elements [2].

Research on wound healing agents is one of the developing areas in modern biomedical sciences and it is shown that the process of wound healing can be promoted by several natural products [3]. Some of these agents are composed of active principles like triterpenes, alkaloids, flavonoids and biomolecules that usually influence one or more phases of the healing process [4].

Propolis is a resinous material that honeybees (A.mellifera L.) collect from living plants, mix with wax and use in construction and adaptation of their nests [5]. In recent years, propolis has been the object of extensive research for its biological activities and therapeutic properties, and therefore, it has gained popularity as a complementary medicine for health amelioration and disease prevention. The chemical composition of propolis is quite complicated and many components such as polyphenols, phenolic aldehydes, sequiterpene quinones, coumarins, amino acids, steroids and inorganic compounds have been identified in propolis samples and the ethanolic extract of propolis has been reported to possess various biological activities such as antibacterial [6-8], antifungal [9-10], antioxidant [11-12], anticarcinogenic [13], anti-inflammatory [14], antinociceptive [15], and immune-stimulating activities $[\mathbf{1 3 , 1 6}]$. The chemical composition and biological activities 


\section{International Journal of Innovative Research in Medical Sciences (IJIRMS) \\ ISSN (Online): 2455-8737, Vol. 01, Issue 07, Sept 2016 \\ Available online at - www.ijirms.in}

of propolis depends on many different factors such as the geographical region, collecting time, and plant source [7].

Propolis has a long history of medicinal use for various purposes, and especially because of its antimicrobial properties topical application of propolis to wounds has been found to be effective in controlling infection and producing a clean granulating bed [17]. It is suggested that biocellulose /propolis membrane may favor tissue repair in less time and more effectively in contaminated wounds [18].

Propolis is also known to accelerate the burned tissue repair by stimulation of the wound bed glycosaminoglycan accumulation needed for granulation, tissue growth, and wound closure whereas it also accelerates chondroitin/dermatan sulfates structure modification responsible for binding growth factors playing the crucial role in the tissue repair [19]. Topical application of propolis can accelerate wound healing in diabetes. As neutrophil infiltration is normalized, its mechanism of action may be through anti-inflammatory pathways [20]. Moreover, the anti-inflammatory action of propolis mediated by mast cells may be more effective than dexamethasone in the inflammatory phase of healing [21]. It is widely acknowledged that propolis down-regulates type I allergy and inflammation by affecting mast cells, but the effecting component of propolis, which cause these effects, still remain unknown [22].

Based on its use in wound healing in traditional practices and research literature, the present study was undertaken to evaluate wound healing activity of ethanolic extract of propolis(EEP) in Wistar albino rats.

\section{Materials and Methods}

\subsection{Propolis sample and ointment formulation}

Propolis sample was collected from Bursa in Turkey (West Anatolia). Hand collected propolis was kept desiccated and in the dark up to their processing. Voucher specimen is deposited in the Department of Microbiology, Faculty of Medicine, University of Erciyes, Kayseri. An aliquot of crude propolis $(7 \mathrm{~g})$ was dissolved in $80 \%$ ethanol by shaking at $50^{\circ} \mathrm{C}$ for 3 days and protected from light. The aqueous-ethanol extract was filtered through a Whatman 1 paper and concentrated at $50^{\circ} \mathrm{C}$. The resin obtained was dissolved in $80 \%$ ethanol to a final concentration of 100 $\mathrm{mg} / \mathrm{ml}$. This final solution was employed for the antibacterial assays. Petroleum jelly obtained from Merck Chem was used as a base material in the $30 \%(\mathrm{w} / \mathrm{w})$ propolis ointment formulation.

\subsection{Chemical analysis of propolis sample}

$30 \mathrm{~g}$ propolis sample was extracted for a week with $100 \mathrm{ml}$ of $70 \%$ ethanol, at room temperature. After filtration the extract was evaporated to dryness at $50^{\circ} \mathrm{C}$ under vacuum conditions. In this study, one mg of dry extract was reacted with $50 \mu \mathrm{l}$ pyridine and $100 \mu \mathrm{l}$ bis (trimethylsilyl) trifluoroacetamide (BSTFA) including $1 \%$ trimethylchlorosilane (TMCS) in a sealed glass tube at $100 \mathrm{oC}$ for $30 \mathrm{~min}$ and sample was prepared for gas chromatography and one $\mu \mathrm{l}$ of a sample was injected and analyzed by GC-MS [23].

Gas chromatography-mass spectrometry was carried out on an Agilent GC 6890 gas chromatograph coupled to an Agilent MSD 5973 mass detector under electron impact ionization. The chromatographic column for the analysis was Zebron (ZB-1) methyl polysiloxane column (30 m x $0.25 \mathrm{~mm}$ ID x $0.25 \mu \mathrm{m}$ df). Helium was used as a carrier gas at a flow rate of $10 \mathrm{ml} / \mathrm{min}$. Propolis sample was analyzed with the column held initially at $100^{\circ} \mathrm{C}$ for $5 \mathrm{~min}$ and then increased to $150^{\circ} \mathrm{C}$ and then kept at $150^{\circ} \mathrm{C}$ for $2 \mathrm{~min}$. Finally, temperature was increased to $280^{\circ} \mathrm{C}$ with a ramp rate $2^{\circ} \mathrm{C} / \mathrm{min}$ and it was kept constant at $280^{\circ} \mathrm{C}$ for $60 \mathrm{~min}$. The injection was performed in split mode at $250^{\circ} \mathrm{C}$. Peaks were identified by computer searches in commercial reference libraries. The components of ethanol extract of propolis were determined by considering their areas as percentage of the total ion current.

\subsection{Antimicrobial activity}

Antimicrobial activity of propolis was studied against pathogens namely Staphylococcus aureus, Escherichia coli, Pseudomonas aeruginosa and Streptococcus sp. These organisms were acquired from infected wound sites of patients in Erciyes University, Gevher Nesibe Hospital in Kayseri, Turkey. Antimicrobial activity of propolis was determined by the agar dilution method, following the National Committee of Clinical Laboratory Standard guidelines (NCCLS, 1997). Bacterial strains were grown on Mueller Hinton agar (Oxoid) at $37^{\circ} \mathrm{C} / 24 \mathrm{~h}$. The turbidity of the bacteria suspension was adjusted to an equivalent 0.5 McFarland standard.

Each antimicrobial test also included plates containing the culture medium plus ethanol, in order to obtain a control of the solvent antimicrobial effect. Propolis extracts were added in arithmetical progression. The concentration of propolis in the media was expressed in $\mu \mathrm{g}$ per $\mathrm{ml}$. After the inoculation procedures, plates were incubated at $37^{\circ} \mathrm{C} / 24 \mathrm{~h}$ and MIC endpoints were read as the lowest concentration of propolis that resulted in no visible growth on the surface of the culture medium.

\subsection{Animals and grouping}

Twenty-one male Wistar albino rats (150-180 g) were used for the study. The rats were randomly divided into three groups consisting of seven in each group, where Group1 animals were topically treated with propolis ointment and Group 2 animals were topically treated with Thiocillin ${ }^{\circledR}$ (Bacitracin $15000 \mathrm{IU} /$ Neomycin Sulphate $150 \mathrm{mg}$ ) while Group 3 as the control group was topically treated with 


\section{International Journal of Innovative Research in Medical Sciences (IJIRMS) \\ ISSN (Online): 2455-8737, Vol. 01, Issue 07, Sept 2016 \\ Available online at $-w w w$.ijirms.in}

petroleum jelly that was used as a base material in the propolis ointment formulation. The rats were kept individually in standardized environmental conditions, provided with pellet rodent diet and water ad libitum. The protocol of this study was approved by the Ethics Committee of Erciyes University.

\subsection{Wound model}

All the groups were studied respectively on incision wound model in rats. Animals in each group were anesthetized and a paravertebral-long incision was made through the skin and cutaneous muscles at a distance of about $1.5 \mathrm{~cm}$ from the midline of the depilated back of the rats as described by Yesuf \& Asres [24]. Full aseptic measures were not taken and no local or systemic antimicrobials were used throughout the study. The Propolis extract ointment and Thiocillin® (Bacitracin 500IU/g, Neomycin sulfate $5 \mathrm{mg} / \mathrm{g}$ ) ointment were administered once daily for 30 days and the mean thickness values of epidermis at the $30^{\text {th }}$ day were used to compare wound healing in the groups. From the healed wound of each rat, three tissue specimens were isolated for calculating the mean values of epidermal thicknesses in each group.

\subsection{Histochemical analysis}

Application of ointments was done daily and treated wound tissues were collected for histological study. The healing tissues obtained on the $30^{\text {th }}$ day from all groups of animals of the incision wound model were processed for histological study. A specimen sample of the tissue was isolated from the healed skin of each group of rats for the histopathological examination. The cross sectional full thickness epidermis specimens from each group were collected at the end of the study. Granulation tissue specimens were collected at regular intervals of 2 days. All samples were fixed in $10 \%$ buffered formalin, processed and blocked with paraffin and then sectioned into 5-7 $\mu \mathrm{m}$ thick sections and stained with haemotoxylin and eosin [25].

\subsection{Statistical analysis}

Results were expressed as Mean \pm SD. Differences between group means were calculated by one-way analysis of variance (ANOVA) and the results were considered statistically significant at $\mathrm{p}<0.05$.

\section{Results}

The main compounds of propolis are flavonoids (pinobanxin and galangin), aromatic and fatty acids and their esters, alcohols, esters and ketones.(Table 1.)

The EEP sample exhibited in vitro antibacterial activity. All of the assayed bacterium species were susceptible to propolis extract. S.aureus was the most sensitive strain and it was susceptible to low propolis concentration $\left(\mathrm{MIC}_{90}\right.$ : $<0.1 \mu \mathrm{g} / \mathrm{ml}$ ). On the other hand Gram-negative bacteria growth was only inhibited in higher propolis concentrations.
The $\mathrm{MIC}_{90}$ of propolis against $P$. aeruginosa and E.coli strains was $3.5 \mu \mathrm{g} / \mathrm{ml}$. The MIC range of propolis against Streptococcus spp. was <0.1-1.75 $\mu$ g (Table 2).

In the groups treated by propolis ointment and Thiocillin ${ }^{\circledR}$ ointment the wounds showed epithelisation and the wound margins had no oedema by the $7^{\text {th }}$ day. Histologically, early attenuation of acute inflammatory changes, control of infection and early reparative activities were observed in the propolis treated group in comparison with the control group (Figure 1and 2). The progress of healing on incision wound method induced by the propolis ointment and Thiocillin® ointment as well as the respective control group is measured by using the mean values of epidermal thickness values. It is observed that the epidermal thickness values in the groups of propolis ointment and Thiocillin ${ }^{\circledR}$ ointment were significantly greater than that of the control group, while the epidermal thickness values of propolis ointment group was significantly greater than that of both Thiocillin ${ }^{\circledR}$ ointment treated group and the control group $(\mathrm{P}<0.05)$ (Table 3$)$.

\section{Discussion}

The EEP sample displayed the typical pattern of "poplar type" propolis. It contains the combination of secondary metabolites characteristics for the buds of Populus spp. of the section of Aigeiros [5]. The bud exudates of poplar trees (Populus spp.) are the main source of European and North American propolis [26]. It was confirmed that the propolis sample obtained from Western Anatolia contained typical poplar flavonoid aglycones [27-28]. Also recent studies on Turkish propolis have shown that the main source of the propolis was poplar exudates [29-30].

Infection is one of the most common complications causing delay in wound healing, therefore infection control is important in wound healing. Staphylococcus aureus ( $S$. aureus), Pseudomonas aeruginosa (P. aeruginosa), and $\beta$ hemolytic streptococci are common bacteria in infected wounds [31-32]. Antibacterial effect of propolis has been shown by numerous studies [33-34]. In the present study, the wounds treated with propolis ointment did not exhibit any sign of infection and propolis exhibited in vitro antibacterial activity against Staphylococcus aureus, Escherichia coli, Streptococcus sp. and Pseudomonas sp. presumably propolis acted as an antibacterial medium and prevented bacterial growth.

We found that S.aureus is susceptible to low propolis concentration. Several authors also showed an efficient propolis antibacterial action on S.aureus strains [35-36]. On the other hand Gram-negative bacteria growth was inhibited only in higher propolis concentrations.

These results are in agreement with those of Grange and Davey [36], who observed a marked action of propolis against Gram - positive bacteria and limited activity against 
Gram - negative ones. Epidermal regeneration of a wound is a complex process in which residual epithelial cells proliferate in an integrated manner to form an intact epidermis. Infection is one of the most common complications causing delay in wound healing. Therefore prevention of infection is the primary aim of treatment of wounds so that there is an optimal regeneration of the cells. Recently topical application of propolis has been recognized to be effective in controlling infection and producing a clean granulating wound bed $[\mathbf{1 7}, \mathbf{3 7}]$.

In addition to this, early dermal and epidermal regeneration in the propolis treated rats also confirmed that the propolis extract had a positive effect toward cellular proliferation, granulation tissue formation and epithelisation. The histological study of the tissues of the wound area treated with propolis ointment, Thiocillin ${ }^{\circledR}$ ointment and the control group revealed that in the case of the skin wounds treated with propolis ointment, fibrosis was relatively less and the original tissue regeneration was much better. The skin adrenal structures such as the pilosabecaeous glands, sweat glands etc. were better presented in the wounds treated with propolis ointment compared to Thiocillin ${ }^{\circledR}$ treated wounds. Previously, Morales and Garbarino [38] stated that the usage of propolis in the treatment of different cutaneous lesions of such as burns, wounds and ulcers is positive in the reparation process, shortening the healing of wounds and reducing the risk of infections. By minimizing acute inflammatory exudate and stimulating macrophage and CD4 T lymphocyte activity, propolis may play a positive effect in wound healing [39].

Besides its antimicrobial activity, the wound healing property of propolis may probably be due to the presence of bioflavonoids which are plant derived substances with strong antioxidant activity. It is supposed that bioflavonoids may also help to relieve pain by inhibiting prostaglandin cyclooxygenase, lipooxygenase and phospholipase [40]. In addition to this apparent enzyme inhibition, bioflavonoids have demonstrated enzyme activation -namely that of praline hydroxylase, an enzyme necessary for collagen crosslinking [40]. Additionally, some bioflavonoids bind to skin elastic fibres, preventing its degradation by elastases markedly affect the rate of degradation by elastases released as a result of inflammation [41].

Better epithelisation suggests prohealing activity and propolis is able to enhance the reepithelization process [20]. Propolis ointment shows a significant prohealing activity when topically applied on rats. Better epithelisation seen under the influence of propolis extract may be because of the presence of flavonoids, which is responsible for the free radical scavenging activity, that is supposed to be an important component of wound healing also [42].

Restoration of the epithelial thickness is a proliferative stage in wound healing. Epidermal healing is characterized by a reepithelialization process and better epithelisation suggests prohealing activity. Therefore, an optimal increase in epithelial thickness can be used as a marker of improved healing. In contrast to this, the lack of reepithelialization is an indicator of decline of wound healing

while an extreme increase can be an indicator of delayed remodeling process. In this preliminary study, it was attempted to compare the epidermal thickness in the control and the treated wounds (by Thiocillin ${ }^{\circledR}$ ointment and Propolis ointment), just to determine whether propolis ointment may be effective in closing the wounds or not. Further study in depth is necessary to probe into the exact mechanism.

\section{Conclusion:}

Wound healing is a complex biological process that consists of precisely and highly programmed phases. Infection can lead to elongate the inflammatory phase and then the wound in a chronic state may fail to heal. Many chronic wounds do not heal because of the failure of antibiotics.

Propolis is an antibacterial, antioxidant and antiinflammatory agent. It can be used as a topical agent, which does not adhere to surface and it has been found to be effective in controlling infection and producing a clean granulating bed. Propolis ointment may be an efficient topical therapeutic agent for wound treatment because it appears to promote reepithelisation and decrease prolonged inflammatory reaction. In addition, propolis treatment of superficial wounds is cost effective because it shortens the duration of treatment.

The result of the present study suggests that EEP posseses a potent wound healing activity, thereby justifying its use in indigenous medicine. Further pharmacological, biochemical investigation will clearly elucidate the mechanism of action and under internationally acceptable quality control propolis can constitute a potential evidence based complementary therapeutic agent for wound healing in integrative medicine.

\section{Acknowledgements}

The authors express their sincere thanks to Erkut SOMAK for his help in conducting the study and also the histologists, Prof. Narin LIMAN and Asst. Prof. Melek Koçak HAREM, for preparing the histological slides and their interpretation. 
International Journal of Innovative Research in Medical Sciences (IJIRMS)

ISSN (Online): 2455-8737, Vol. 01, Issue 07, Sept 2016

Available online at -www.ijirms.in

Table 1. Chemical composition of propolis

\begin{tabular}{|c|c|c|c|}
\hline Compounds & RT & Compounds & RT \\
\hline Organic acids & & Flavonoids & \\
\hline Octadecanoic acid & 46.89 & Pinobanxin & 21.85 \\
\hline $9,12,15$ Octadecanoic acid & 14.58 & Galangin & 24.44 \\
\hline Tetradecanoic acid & 20.96 & Esthers & \\
\hline Undecanoic acid & 51.21 & 4,3 acetyloxycaffeate & 34.84 \\
\hline Oleic acid & 30.92 & 2-propenoic acid esther & 11.81 \\
\hline Aromatic acids & & Cafeic acid TMS esther & 36.21 \\
\hline Benzoic acid & 5.87 & Ketons & \\
\hline Caffeic acid & 29.19 & Cyclohexanon & 19.55 \\
\hline Palmitoleic acid & 31.19 & 3-methyl antitricyclo undec-3-en-10-on & 21.52 \\
\hline Alcohols & & Hydrocarbons & \\
\hline Pentitol & 45.18 & Cyclohexane & 51.21 \\
\hline Ribitol & 20.96 & Cyclopentene & 50.31 \\
\hline Vaniletanediol & 38.78 & 5-n-propyl-1,3 dihydroxybenzene & 42.19 \\
\hline Bicyclohept-3-en-2-ol & 14.72 & & \\
\hline
\end{tabular}

RT: Retention time

(The peak numbers in the table are given according to the retention time only to the major peaks)

Table 2. Minimum inhibitory concentration (MIC) of propolis using agar dilution method

\begin{tabular}{|l|l|l|l|}
\hline Microorganisms & MIC $_{\mathbf{5 0}}(\boldsymbol{\mu g} / \mathbf{m l})$ & $\mathbf{M I C}_{\mathbf{9 0}}(\boldsymbol{\mu g} / \mathbf{m l})$ & MIC $\mathbf{~ r a n g e ~}(\boldsymbol{\mu g} / \mathbf{m l})$ \\
\hline Staphylococcus aureus $(\mathrm{n}=5)$ & $<0.1$ & $<0.1$ & $<0.1$ \\
\hline Escherichia coli $(\mathrm{n}=6)$ & 3.50 & 3.50 & $1.75-3.50$ \\
\hline Streptococcus spp. $(\mathrm{n}=4)$ & $<0.1$ & 0.2 & $<0.1-1.75$ \\
\hline Pseudomonas spp. $(\mathrm{n}=4)$ & 3.5 & 3.5 & 3.5 \\
\hline
\end{tabular}

Table 3. Thickness of epidermis of treatment and control groups $(\mathbf{p}<0.05)$

Thickness of epidermis at $30^{\text {th }}$ day $(\mathrm{mm})($ Mean \pm SD)

\section{Groups}

Propolis ointment

Thiocillin® ointment

Control
Min.

Max.

4.44

2.66

$3.96 \pm 0.41^{\mathrm{b}}$

1.80

3.38 


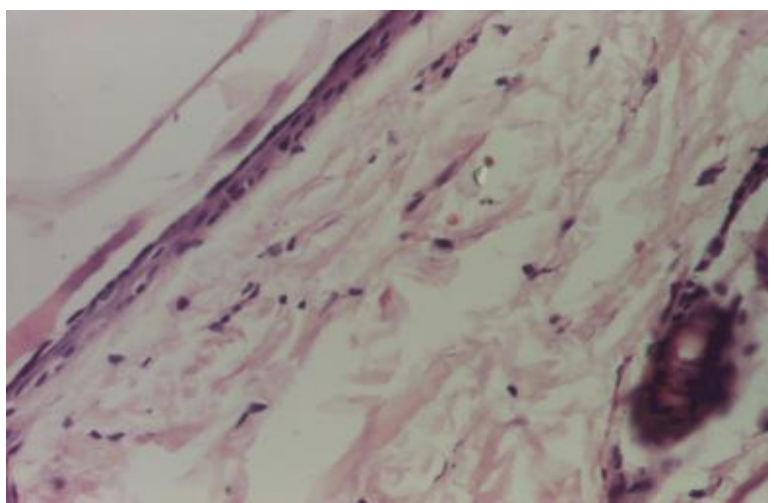

Figure 1. Dermis of the control group (HEx200).

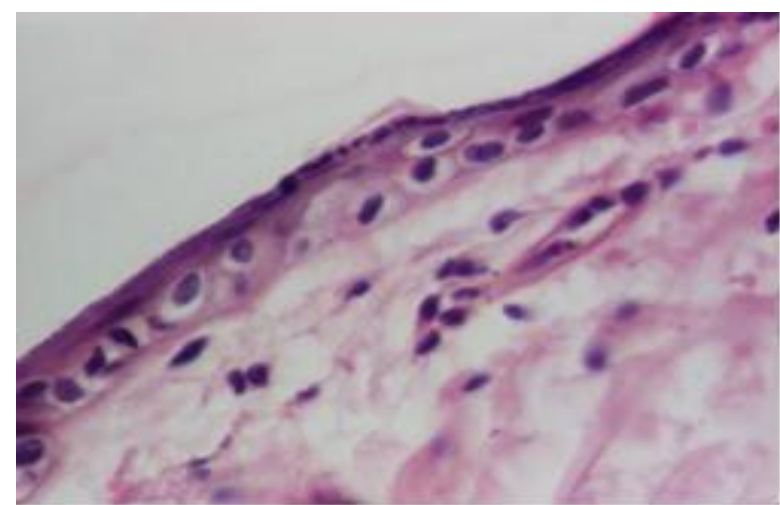

Figure 2 The regenerated epithelium and perivascular fibroblasts of propolis group (HEx400).

\section{References}

1. Diegelmann RF, Evans MC: Wound healing: an overview of acute, fibrotic and delayed healing. Front Biosci 2004;9: 283-289.

2. Broughton G, Janis JE, Attinger CE: The basic science of wound healing. Plast Reconstr Surg (7 Suppl) 2006;12S-34S.

3. Kumar B, Vijayakumar M, Govindarajan R: Ethnopharmacological approaches to wound healing - Exploring medicinal plants of India. J Ethnopharmacol 2007;114: 103-113.

4. Sumitra M, Manikandan P, Suguna L: Efficacy of Butea monosperma on dermal wound healing in rats. Int J Biochem Cell Biol 2005;37(3): 566-573.

5. Bankova VS, Castro SL, Marcucci MC: Propolis: Recent advances in chemistry and plant origin. Apidologie 2000;31: 3-15.

6. Keskin N, Hazır S, Baser KHC: Antibacterial activity and chemical composition of Turkish propolis. Z. Naturforsch 2001;56 c:1112-1115.7.
7. Popova M, Silici S, Kaftanoglu O: Antibacterial activity of Turkish propolis and its qualitative and quantitative chemical composition. Phytomedicine 2004;12 (3): 221-228.

8. Silici S, Kutluca S: Chemical composition and antibacterial activity of propolis collected by three different races of honeybees in the same region. $\mathbf{J}$ Ethnopharmacol 2005;99(1): 69-73.

9. Koc, AN, Silici S, Ayangil D: Comparison of in vitro activities of antifungal drugs and ethanolic extract of propolis against Trichophyton rubrum and T.mentagrophytes by using a microdilution assay. Mycoses 2005;48: 205-210.

10. Ota C, Unterkircher C, Fantinato V: Antifungal activity of propolis on different species of Candida. Mycoses 2001;44: 375-378.

11. Simões LMC, Gregório LE, da Silva Filho AA: Effect of Brazilian green propolis on the production of reactive oxygen species by stimulated neutrophils. J Ethnopharmacol 2004;94:59-65.

12. Kolonkaya D, Selmanoglu G, Sorkun K: Protective effects of Turkish propolis on alcohol-induced serum lipid changes and liver injury in male rats. Food Chem 2002; 78 (2): 213-217.

13. Burdock GA: Rewiev of the biological properties and toxicity of bee propolis. Food Chem Toxicol 1998;36(4): 347-363.

14. Miyataka H, Nishiki M, Matsumoto H: Evaluation of propolis. Part I: evaluation of Brazilian and Chinese propolis by enzymatic and phsicochemical methods. Biol Pharm Bull 1997;20: 496501 .

15. Talla E, Dabole B, Taiwe GS: Evidence by in vivo and in vitro studies that binding of pycnogenols to elastin affects its rate of degradation by elastases. Biochem Pharmacol 1984;33(24): 3933-39.

16. Yeunhwa Gu, Kaida $\mathrm{T}$, Kaida $\mathrm{K}$ : Immunostimulating and Antitumor Effects by Inonotus obliquus (Ach.:Pers.) Pilat. Int $\mathrm{J}$ Med Mushrooms 2005;7(3):406.

17. Öztürk F, Kurt E, İnan UU: The effects of acetylcholine and propolis extract on corneal epithelial wound healing in rats. Cornea 1999;18 (4): 466-471. 
18. Hernane SB, Araujo Junior AM, Saska, S: Ultrastructural view of colon anastomosis under propolis effect by transmission electron microscopy. World J Gastroenterol 1983;14(30): 4763-4770.

19. Pawel Olczyk, Grzegorz Wisowski, Katarzyna Komosinska-Vassev: Propolis Modifies Collagen Types I and III Accumulation in the Matrix of Burnt Tissue. Evidence-Based Complementary and Alternative Medicine DOI:10.1155/2013/423809.

20. McLennan SV, Bonner J, Milne S: The antiinflammatory agent Propolis improves wound healing in a rodent model of experimental diabetes. Wound Repair Regen 2008;16(5):706-13.

21. Barroso PR, Lopes-Rocha R, Pereira EM: Effect of propolis on mast cells in wound healing. Inflammopharmacol 2012;20(5):289-94

22. Chirumbolo S: Flavonoids in propolis acting on mast cell-mediated wound healing Inflammopharmacol 2012;20 (2): 99-101.

23. Silici S, Koc AN: Comparative study of in vitro methods to analyse the antifungal activity of propolis against yeasts isolated from patients with superficial mycoses. Lett Appl Microbiol 2006;43: 318-324.

24. Adem Yesuf Dawed, Kaleab Asres: Evaluation of the wound healing and antiinflammatory properties of extracts from the leaves of Allophylus abyssinicus (Hochst.) Radlk. Phytopharmacology 2013;4(2); 442-453.

25. Mc Manus JFA, Mowry RW . Staining methods: Histologic and histochemical, Paul B. Hoeber Inc., New York. 1960, pp 423.

26. Velikova M, Bankova V, Sorkun K: Türkiye ve Bulgaristan kökenli propolis örneklerinin kimyasal bileşimi ve biyolojik aktiviteleri, Mellifera 2001;1(1): 24-26.

27. Sorkun K, Süer B, Salih B: Determination of chemical composition of Turkish propolis. Z. Naturforsch 2001;56 c: 666-668.

28. Silici S, Unlu M, Vardar-Unlu G: Antibacterial activity and phytochemical evidence for the plant origin of Turkish propolis from different regions. World J Microbiol Biotechnol 2007;23: 17971803 .
29. Vardar-Unlu G, Silici S, Unlu M: Composition and in vitro antimicrobial activity of Populus buds and poplar-type propolis. World J Microbiol Biotechnol 2008;24: 1011-1017.

30. Sforcin JM, Fernandes Jr A, Lopes CAM: Seasonal effect on Brazilian propolis antibacterial activity. J Ethnopharmacol 2000;73: 243-249.

31. Edwards R, Harding KG (2004). Bacteria and wound healing. Curr Opin Infect Dis 2004;17: 9196.

32. Davis SC, Ricotti C, Cazzaniga A, Welsh E, Eaglstein WH, Mertz PM:Microscopic and physiologic evidence for biofilm-associated wound colonization in vivo. Wound Repair Regen 2008;16: 23-29.

33. Srdjan Stepanovića, Nataša Antića, Ivana Dakića, Milena Švabić-Vlahovića. In vitro antimicrobial activity of propolis and synergism between propolis and antimicrobial drugs. Microbiological Research 2003; 158(4):353-357

34. F. Scazzocchioa, F.D. D’Auriaa, D. Alessandrinia: Multifactorial aspects of antimicrobial activity of propolis. Microbiological Research 2006;161(4):327-333.

35. Fernandes JrA, Sugızakı MF, Fogo MI: In vitro activity of propolis against bacterial and yeast pathogens isolated from human infections. J Venom Anim Toxins 1995;1: 63-69.

36. Grange JM Davey RW: Antibacterial properties of propolis (bee glue). J Royal Soc Med 1990;83: 159-160.

37. Dobrowolski JW, Vohora SB, Sharma K: Antibacterial, antifungal, antiamoebic, anti inflammatory and antipyretic studies on propolis bee products. J Ethnopharmacol 1991;35: 77-82.

38. Morales WF, Garbarino L: Clinical evaluation of a new hypoallergic formula of propolis in dressings. Bee Products, edited by Mizrahi and Lensky, Plenum Press, New York 1997;101-105.

39. Sibel Serin Kilicoglu, Bulent Kilicoglu, Esra Erdemli: Ultrastructural view of colon anastomosis under propolis effect by transmission electron microscopy. World J Gastroenterol. 2008 Aug 14; 14(30): 4763-4770. 
40. Havsteen B: Flavonoids, a class of natural products of high pharmacological potency. Biochem Pharmacol 1983 :32(7):1141-48.

41. Tixier JM, Godeau G, Robert AM: Evidence by in vivo and in vitro studies that binding of pycnogenols to elastin affects its rate of degradation by elastases. Biochem Pharmacol 1984;15;33(24):3933-9.

42. Asha BA, Nagabhushan G, Shashikala H: Study of wound healing activity of topical Ocimum sanctum Linn in albino rats. J Chem Pharm Res 2011 ; 3(6) :122-126. 